\section{Plants in peril: how shall we save them?}

The statistics are frightening. 'As many as 100,000 of the estimated total 300,000 vascular plant species may be gone or on the way to extinction by the middle of the next century', said Peter Raven (1999), Director of the Missouri Botanical Garden, at the Millennium Symposium delivered in August to the XVI International Botanical Congress in Missouri. 'If we do not take action now, by the end of the century we may have destroyed two-thirds of the plant species we currently use and enjoy'. Yet even these terrifying figures mask the widespread denudation of plants that will not become extinct, but whose populations have been, and will continue to be, decimated over much of their range.

What will we do? It is true that plants are in some ways easier to conserve than other groups of organisms. They can be grown in botanical gardens, and the seeds of many species, particularly those from arid regions, can be stored in seed banks. But even with our best efforts, our grandchildren may inhabit a world where a huge proportion of currently wild plant species will occur only as specimens.

This rationale lies at the heart of the sea change taking place in the Species Survival Commission (SSC) of the World Conservation Union (IUCN). At the heart of their new Plants Programme, launched at the XVI Botanical Congress, is an approach to plant conservation based on Important Biodiversity Areas. At a global level, the approach will be underpinned by the 'Centres of Plant Diversity' (CPDs), as described in the threevolume work published by IUCN and WWF-compiled as a response to concern about rapid global loss and degradation of natural ecosystems (WWF \& IUCN, 1994-1997). These areas face a gamut of threats ranging from climate change to intensive agriculture, tourism and soil erosion. Although volume 1 was published in 1994, the work has been underused as a plant conservation tool.

On a continental level, the approach will be to identify 'Important Plant Areas' (IPAs). In Europe, for instance, the identification of candidate 'Special Areas for Conservation' under the European Union's (EU) Habitats and Species Directive is pinpointing areas of nature conservation importance in EU countries, which, along with the 'Special Protection Areas' under the EU Birds Directive, will form the Natura 2000 Network. Much work has been carried out in the accession countries to the EU to identify the areas that will eventually become part of the Natura 2000 Network, but there is, as yet, no European-wide view of the most important places for wild plants in the wider Europe. This is why Plantlife, through Planta Europa, is co-ordinating a project to identify European IPAs. Further afield, Fauna \& Flora International has almost completed an inventory of IPAs in Turkey.

What is the rationale for an areas-based approach? It includes but goes beyond the traditional line 'if you save the habitat, you save the plant'. Globally, in the biodiversity arena, botanists and taxonomists are concluding that much work remains to be carried out in order to both describe and classify species. Sir Robert May, UK Government Chief Scientist, for example, estimates conservatively that of as many as $7-10$ million species on the planet, only 1.6 million have been recognized scientifically. Even in north-west Europe rarely do we have a full inventory of species for a site-the vascular plants will be known, but what about the mosses, liverworts, lichens, fungi and algae?

To save wild plants, then, we need to save the places where they grow. And once saved, these places need to be managed appropriately; some species may even need 'in situ maintenance'. This is not rocket science; it sounds simple, but even botanists do not always see the reasoning. Saving these places will give taxonomists the necessary time to identify and name what is there.

For IUCN-SSC, this approach means a refocusing of its activities. SSC is the world's largest network of species conservation experts, comprising some 7000 volunteers (the word is a misnomer because many of these people are conservation professionals). Rigorous criteria need to be developed for identifying, classifying and prioritizing conservation work in the CPDs, alongside the urgent effort needed for conservation. The excellent Action Plans produced for various taxa (the Cactus and Succulent Action Plan is a good example; see Oldfield, 1997) by the Specialist Groups often contain sound information on areas of importance and what needs to be done in order to conserve them. The SSC's new Plants Programme acknowledges that these need to be taken off the shelf, and resources found to implement them.

The Red Data Books are powerful tools for conservation. The size, weight and very redness of them impress decision-makers. Yet, not only are they not enough, but they are also getting more and more difficult-and expensive-to produce, as knowledge on biodiversity increases and countries develop and use different taxonomies. The trick to pull here will be to focus effort on CPDs and IPAs, and to red list species that indicate biodiversity trends. 
challenge, which cannot be met by working in isolation. Genuine collaboration and strategic alliances will be essential. It will be crucial to make links with those charged with implementation of the Biodiversity Convention, to name but one organization. A shift to a more areas-based approach means that alliances will need to be made within the IUCN-the forging of a strong working link with the World Commission on Protected Areas will be fundamental.

The sea changes described here will take some time in an organization whose strength has been a taxonomic approach to plant conservation. Yet there is a widespread belief that to attempt to meet any lesser challenge will do nothing to halt the loss of species or to save the plant life of the planet.

\section{Jane Smart}

Executive Director of Plantlife, Member of the

Planta Europa Steering Committee and Member of the

IUCN-SSC Plant Conservation Committee

\section{References}

Oldfield, S. (1997) Cactus and Succulent Plants. Status Survey and Conservation Action Plan. IUCN/SSC Cactus and Succulent Plant Specialist Group, IUCN, Gland, Switzerland and Cambridge, UK.

Raven, P.H. (1999) Plants in peril: what should we do? Text of an Address to the Millennium Symposium, delivered to the XVI International Botanical Congress, 4 August 1999.

WWF \& IUCN (1994-1997) Centres of Plant Diversity. A Guide and Strategy for their Conservation, 3 vols. IUCN Publications Unit, Cambridge, UK. 